\title{
Correction to: Efficacy of canakinumab as first-line biologic agent in adult-onset Still's disease
}

Giulio Cavalli, ${ }^{1,2,3^{*}}$, Alessandro Tomelleri ${ }^{1,2}$, Giacomo De Luca ${ }^{1,2}$, Corrado Campochiaro ${ }^{1}$, Charles A. Dinarello ${ }^{3,4}$, Elena Baldissera ${ }^{1}$ and Lorenzo Dagna ${ }^{1,2}$

\section{Correction to: Arthritis Res Ther \\ https://doi.org/10.1186/s13075-019-1843-9}

Following publication of the original article [1], the authors reported an error in the spelling of Lorenzo Dagna's name. The authors apologise for the error.

Incorrect spelling:

Loreno Dagna

Correct spelling:

\section{Lorenzo Dagna}

The original article [1] has been updated.

\begin{abstract}
Author details
${ }^{1}$ Unit of Immunology, Rheumatology, Allergy and Rare Diseases, IRCCS San

Raffaele Hospital, Vita-Salute San Raffaele University, Via Olgettina 60, 20132 Milan, Italy. ${ }^{2}$ Vita-Salute San Raffaele University, Milan, Italy. ${ }^{3}$ Department of Medicine, Radboud University Medical Center, Nijmegen, The Netherlands. ${ }^{4}$ Department of Medicine, University of Colorado Denver, Aurora, CO 80045, USA.
\end{abstract}

Received: 19 February 2019 Accepted: 19 February 2019

Published online: 25 February 2019

\section{Reference}

1. Cavalli, et al. Efficacy of canakinumab as first-line biologic agent in adult-onset Still's disease. Arthritis Res Ther. 2019;21:54 https:/doi.org/10.1186/

s13075-019-1843-9.

\footnotetext{
*Correspondence: cavalli.giulio@gmail.com

1 Unit of Immunology, Rheumatology, Allergy and Rare Diseases, IRCCS San

Raffaele Hospital, Vita-Salute San Raffaele University, Via Olgettina 60, 20132 Milan, Italy

${ }^{2}$ Vita-Salute San Raffaele University, Milan, Italy

Full list of author information is available at the end of the article
}

(c) The Author(s). 2019 Open Access This article is distributed under the terms of the Creative Commons Attribution 4.0 International License (http://creativecommons.org/licenses/by/4.0/), which permits unrestricted use, distribution, and reproduction in any medium, provided you give appropriate credit to the original author(s) and the source, provide a link to the Creative Commons license, and indicate if changes were made. The Creative Commons Public Domain Dedication waiver (http://creativecommons.org/publicdomain/zero/1.0/) applies to the data made available in this article, unless otherwise stated. 